\title{
Development of a data driven approach to explore the energy flexibility potential of
} building clusters

\author{
Wang, Andong; Li, Rongling; You, Shi
}

\section{Published in:}

Applied Energy

Link to article, DOI:

10.1016/j.apenergy.2018.09.187

Publication date:

2018

Document Version

Peer reviewed version

Link back to DTU Orbit

Citation (APA):

Wang, A., Li, R., \& You, S. (2018). Development of a data driven approach to explore the energy flexibility potential of building clusters. Applied Energy, 232, 89-100. https://doi.org/10.1016/j.apenergy.2018.09.187

\section{General rights}

Copyright and moral rights for the publications made accessible in the public portal are retained by the authors and/or other copyright owners and it is a condition of accessing publications that users recognise and abide by the legal requirements associated with these rights.

- Users may download and print one copy of any publication from the public portal for the purpose of private study or research.

- You may not further distribute the material or use it for any profit-making activity or commercial gain

- You may freely distribute the URL identifying the publication in the public portal 


\title{
Development of a data driven approach to explore the energy flexibility potential of building clusters
}

\author{
Andong Wang ${ }^{1}$, Rongling $\mathrm{Li}^{2 *}$, Shi You ${ }^{3}$ \\ ${ }^{1}$ Department of Building Science, School of Architecture, Tsinghua University, China \\ ${ }^{2}$ Department of Civil Engineering, Technical University of Denmark, Denmark \\ ${ }^{3}$ Department of Electrical Engineering, Technical University of Denmark, Denmark \\ *Corresponding author: liron@byg.dtu.dk
}

\section{Abstract}

With the growing use of renewable energy sources, the stability of electrical power systems can be seriously affected by fluctuations in the available power. As one of the potential solutions for this new challenge, the energy flexibility of buildings has become a focus for research and technological development. Most studies have focused on single buildings, with only a few studies on building clusters in which the building models were usually oversimplified in that they did not consider different building types or their thermal characteristics, their occupancy or their occupants' behaviour. In this paper, we describe a data driven approach to simulating a generic building cluster that could resemble any mix of building archetypes and occupancy. The energy flexibility potential of apartment building clusters was estimated by using data from surveys and available statistics in Denmark for the worst case scenario, i.e. when the end users do not allow any disturbance when they are at home, so that energy flexibility is only available when residents are not at home. In this scenario, no energy flexibility is assumed when buildings are occupied, which yields a conservative estimation. The uncertainty of the energy flexibility potential due to uncertain occupancy and various archetypes was quantified for different scales of building cluster. The resulting hybrid-model is a combination of a building model and an occupancy model and includes the different factors that influence the potential energy flexibility of buildings. The results show that the uncertainty of the energy flexibility decreases when the aggregated number of buildings increases. The uncertainty of energy flexibility was less than $10 \%$, when about 700 households were aggregated. This approach can be used to simulate building energy flexibility for district or even regional level energy planning when the intention is to use the available flexibility to address the challenges caused by fluctuation in the power available from renewable energy sources.

Keywords

Building cluster; Energy flexibility; Space heating; Occupancy; Uncertainty

\section{Introduction}

The use of renewable energy resources is increasing rapidly. In EU countries, at least $20 \%$ of total energy demand must come from renewables by 2020 (EU 2009). Denmark plans to be fossil-fuel free by 2050 (The Danish Government 2013). The high penetration of intermittently available renewable energy 
sources has already created a desperate need for increased flexibility that would allow a power system to adapt to dynamic and changing conditions, such as balancing supply and demand on different time scales or supporting congestion management at various locations (You et al. 2015). Buildings account for one third of total energy consumption in Denmark and most other developed countries, so creating flexible energy demand in buildings has considerable potential. In future smart cities demand response and the energy (demand) flexibility of buildings are likely to play a significant role.

The energy flexibility in buildings is often quantified as the deviation of electricity consumption under different scenarios of electricity costs and thermal comfort provision (Lopes et al. 2016). Flexibility characteristics were described in detail in a recent publication (Junker et al. 2018). The study was based on the assumption that the system providing flexibility is able to respond to an external penalty signal such as dynamic energy pricing. Six characteristics are then identified as 1) the delay time from energy price changes to the effect appears in energy demand, 2) the maximum power change in demand, 3) the time it takes to reach the maximum power change, 4) the total time of energy demand change, 5) the total decreased demand and 6) the total increased demand. The thermal comfort of building occupants is a constraint on flexible operation, so it has become a common approach to calculate the energy flexibility of buildings, especially regarding heating, ventilation and air-conditioning (HVAC) systems and thermal mass, by using pre-defined upper and lower temperature bounds, such as in (Pallonetto et al. 2016) and (Adhikari et al. 2018). In (Finck et al. 2018) the comfort range was more dynamic with comfort temperature determined using occupancy rate which refers to the ratio of occupants to the maximum amount of occupants.

Demand response and energy flexibility must be implemented at a large scale if the accumulated energy flexibility is to reach a magnitude that can be meaningful for energy providers. To the best knowledge of the authors, there are only a few publications on demand response and energy flexibility at the building cluster level. Vigna et al. (2018) presented an overview of the concept of building clusters and its relevant concepts. A building cluster was defined from the perspective of building and energy grid interaction. In this definition, a building cluster is an aggregation of buildings which can be managed by a common agent such as a utility company, to exploit the energy flexibility of the building cluster. Studies have shown that the energy flexibility of a building is greatly influenced by both building physical characteristics and occupancy pattern of the residents (Masy et al., 2015), (Li et al., 2017a) and (Li et al., 2017b). A review of large scale demand response estimation studies (Goy and Finn 2015) conducted in 2015 concluded that they used oversimplified building models that did not consider different building types or their thermal characteristics and occupants' behavior. Very few studies have appeared since 2015.

(X. Li et al. 2016) developed a forecasting model to investigate resource allocation within a building cluster while maintaining indoor thermal comfort. Three small and medium-sized DOE reference office buildings were included. A smart building cluster was studied for demand response (Ma et al. 2016). In this study, building loads were modelled but not buildings. (Georges et al. 2017) aggregated a set of houses equipped with heat pumps and proposed several ways of achieving flexibility. This comprehensive study included a group of houses representing the Belgian residential building stock with the indoor temperature set to remain within the thermal comfort range at all times. (Adhikari et al. 2018) presented a framework to aggregate residential customers with a demand response aggregator. In this approach the energy flexibility of HVAC systems was deployed by communicating with an Internet-of-Things thermostat at each house. This approach was implemented in a simulation study on the aggregation of 200 houses, whose thermal parameters had been randomly assigned. Until now, studies of building clusters have not paid 
enough attention to the influence of occupancy and occupant behavior and are often performed for a single building archetype. The importance of these missing elements was pointed out by Goy and Finn (2015).

For modelling building clusters, the archetype-based approach is a promising way to consider their diversity. Using this approach, the scaling-up of energy demand can be achieved by multiplying each archetype by the number of buildings represented by each archetype (Buttitta et al. 2017). In considering modelling techniques, "white box modelling" is used to simulate different archetypes, while "grey box modelling", specifically RC models, are promising for the study of large-scale demand response (Goy and Finn, 2015). RC models were used in (Adhikari et al. 2018) for the aggregation of 200 houses.

In terms of the above literature review, the first contribution of the present study is its data driven approach to estimating the energy flexibility potential of building clusters containing various archetypes during the time that they are unoccupied. The second contribution is the quantification of the uncertainty of the available energy flexibility for different scales of building cluster with different numbers of households. This approach is generic and scalable can be used to aggregate any number of dwellings. The value of the uncertainty quantification is in the planning of energy supply. A typical case is when a grid operator must have information on the reliability of deploying a certain number of households and buildings to achieve demand flexibility and balance the grid. Building upon existing state of the art research on energy flexibility in buildings, the present study goes further:

1. The presented model is generic and scalable, implying it can be used to simulate the flexibility of building clusters with three key features: varying the size of a building cluster, flexible combinations of occupancy pattern and building archetypes in each building cluster, and the control solutions applied to enable the provision of building flexibility. Previous studies in this field have tended to focus on only one or two of these three aspects, as discussed in the Introduction and Methodology sections.

2. Each feature of the model is comprehensively modelled and studied based on three different data sources, i.e. TABULA, Danish Statistics and Danish Time Use Survey. Models based on these three data sources are then closely integrated. This combination of data sources is new. On the one hand the study uses Danish information as an example for developing, validating and proving the value of this model; on the other hand, it allows for replicable research if data collected from other sites/countries are available.

A detailed description of the structure of the simulation platform and models is given in Section 2. In Section 3 the results of occupancy modelling and the energy flexibility of building clusters at various scales are presented. Section 4 contains a discussion and our conclusions.

\section{Methodology}

In this study, heat pumps are assumed to be used for space heating to provide energy flexibility. The following principles were applied:

- Heat pumps can be controlled for flexible electricity usage only during the time period when occupants are away, i.e. when the home is unoccupied. This is the worst case scenario, i.e. the minimum amount of flexibility offered by a dwelling assuming that end users do not allow any 
disturbance of their energy supply when they are at home, so external control can only be applied when they are not at home.

- The occupancy pattern is considered at the household level.

The energy flexibility is thus defined as the adjustable range of heat pump power during the period the apartments are unoccupied. Due to the stochastic nature of occupancy in households, the energy flexibility in this study is a probabilistic distribution with uncertainties instead of a determined number. The uncertainty of energy flexibility can be defined as the degree of dispersion of the distribution. Our hypothesis is "The stochasticity of occupancy declines with the scaling-up of a building cluster, as does the uncertainty of energy flexibility".

A data-driven approach was developed to model the energy flexibility of a building cluster, using MATLAB. The energy flexibility of a given building cluster is greatly influenced by the physical characteristics of the building and the occupancy pattern of individual households. A hybrid-model approach was used that consists of two parts: RC models for the buildings with each building represented as one RC mode, and occupancy models for buildings considering occupancy at the household level. The construction of the model is flexible, in that a building cluster can in principle be modeled with any mix of parameters such as the number of buildings, building types and construction year. Fig. 1 shows the model structure and simulation diagram. Four steps were used in modelling a single building:

1. RC model of the building was developed based on the TABULA database (Wittchen and Kragh 2012) (TABULA 2015).

2. Statistical data on dwelling size and Danish household size from the Statistics Denmark (2017) was then used to estimate the number of households of each size, i.e. One-person, two-person and threeperson in the modelled building.

3. Data from the Danish Time Use Survey (DTUS) 2008/09 (Bonke and Fallesen 2010) (Barthelmes et al. 2018) was used to generate occupancy models of each size of household, which were then used to generate the occupancy model of the building according to the number of households of each size the building contains.

4. The RC model and the occupancy model of the building were integrated, then simulation was started for this building.

For simulating a cluster of buildings, the four steps above were applied to all the buildings. After the simulation of each building, the decision to end or continue the simulation was therefore based on whether the building simulated was the last building in the cluster. If it was, then the simulation ends; if not, it continues with the next building. This is a generic approach that can be used to simulate any dwelling types and to aggregate of any number of dwellings. Each step is explained in more detail in the following section. 


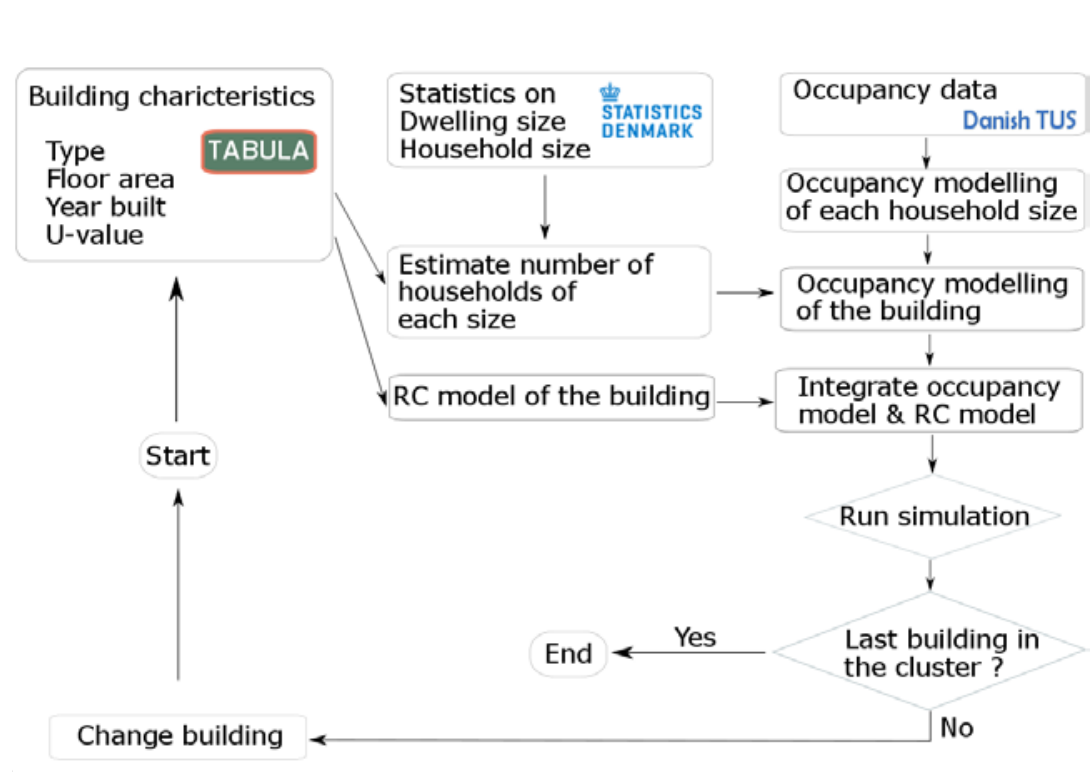

Fig. 1 Flow diagram of quantification of building cluster energy flexibility using a data-driven approach

\subsection{Occupancy modelling}

Occupancy models were developed using occupancy data from DTUS 2008/09, which consists of 9640 individuals and 4679 households. Individuals' daily activities were logged in two diaries, one for a weekday and another for a weekend day with 10 min intervals starting at 4:00 and ending at 3:50 the next day (Barthelmes et al., 2018), (Bonke and Fallesen, 2010). In this study, only weekdays were considered, as on weekends the unoccupied time is much shorter for residential buildings and the pressure on the energy grids is usually less in comparison with weekdays.

Based on Statistics Denmark (2017), 84\% of the households living in apartment buildings consist of no more than three members. Data for households with one to three persons from the DTUS were used in this study. The data consists of 1641 one-person households, 1980 two-person households and 448 threeperson households. The occupancy patterns of one-person households, two-person households and three-person households are shown in Fig. 2, generated from the same data source presented in (Barthelmes et al., 2018). Black color indicates the time when no one is at home. 


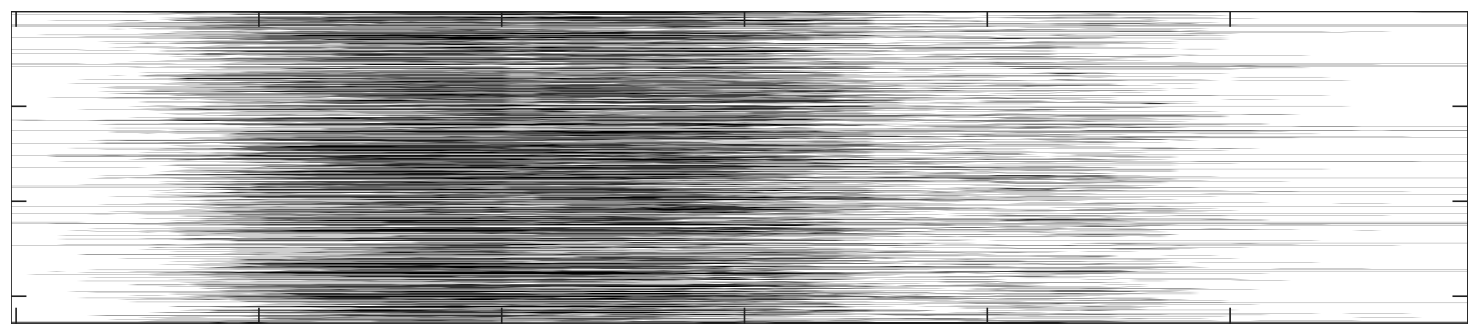

\section{Accepted manuscript}

Fig. 2 Occupancy pattern of households, black: vacancy, white: occupancy. The data consists of 1641 one-person households, 1980 two-person households and 448 three-person households.

The remainder of this section describes the process used for occupancy modelling. The same process was applied to modeling all three types of household.

\subsubsection{Occupancy data resampling}

Bootstrapping is a statistical method with many advantages and is widely used. Bootstrapping relies on random sampling with replacement (Mooney, et al. 1993). In this study, the method was used to estimate the distribution of vacancy percentage of a certain observation point at a certain sample size of a certain household size by random sampling with replacement from the limited DTUS data. We resampled the data by randomly dividing $N$ households into $X$ samples in which each sample contained $Y(n, 2 n, 3 n \ldots)$ households for each household size (one-person, two-person and three-person) using the Bootstrapping method. Limited by the total number of each type of household, we predefined $n=100$ for one-person households, $n=50$ for two-person households and $n=33$ for three-person households. For example, in the case of 1641 one-person household, the data processing steps were as follows. 
1. Sample size: 100 households.

2. Randomly divide 1641 households into 16 groups in which each group contains 100 households.

3. Repeat Step 2 several times (In this study, 10 times).

4. Obtain 160 samples by random sampling with replacement.

5. Change sample size to $200,300,400 \ldots$ And for each sample size, repeat Step 2-4.

Then, a process similar to steps 1-5 was applied to 1980 two-person households and 448 three-person households. The result of above data resampling was a 5D matrix as shown in Equation (1).

OccupancyData (household serial number, timeline, sample serial number, sample size, household size )

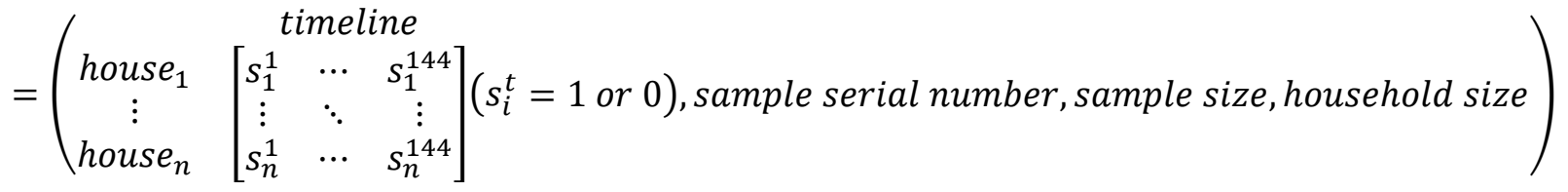

\subsubsection{Vacancy profiling based on Normal Distribution Probability}

The following process was applied on data in the 5D matrix OccupancyData shown in Equation (1).

Take the case of a one-person household and sample size of 100 households as an example shown in Equation (2). Equation (2) is the 3D matrix of Equation (1) with sample size and household size pre-defined. For cases of other sample size and other household size, the data process method was similar.

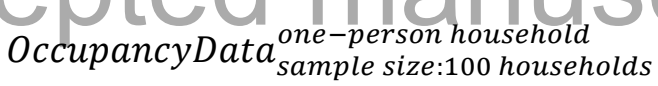

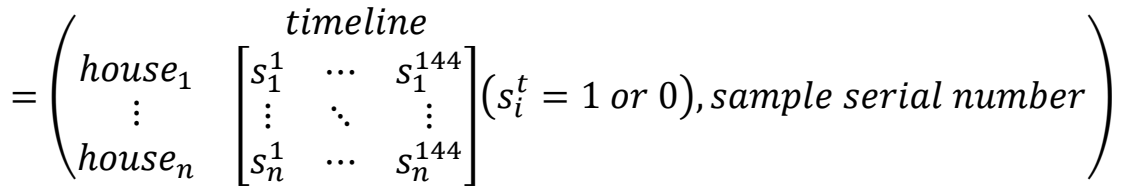

The 3D matrix's size is $100 \times 144 \times 160$ (100 households, the length of the timeline: 144,160 samples). The time interval was $10 \mathrm{~min}$. There were thus 144 observation states (also can be called time points) of one day. For every time point, the vacancy percentage of 100 households was calulated. As there were 160 samples, for every time point, the calculation was repeated 160 times. For every time point, there were therefore 160 vacancy percentage values. As there were 144 time points, in the end, a 2D matrix (160x144) of vacancy percentage can be generated, as shown in Equation (3).

VacancyPercentage $_{\text {sample size } 100 \text { households }}^{\text {one-person housold }}=\left(\begin{array}{c}\text { timeline } \\ \text { sample serial number }_{1} \\ \vdots \\ \text { sample serial number }_{n}\end{array}\left[\begin{array}{ccc}p_{1}^{1} & \cdots & p_{1}^{144} \\ \vdots & \ddots & \vdots \\ p_{n}^{1} & \cdots & p_{n}^{144}\end{array}\right]\right)$

Where $p_{i}^{t}$ is vacancy percentage of sample $i$ at time $t$. Here, $n$ is 160 .

A Normality Test ( $95 \%$ confidence) was made on these 160 vacancy percentages at each time point. This means the Normality Test was repeated 144 times. After all the tests, it was found that the result of $68 \%$ 
of the tests was positive, which means the distribution of vacancy percentage at a certain time point conforms to a normal distribution. This is expressed in Equation (4).

VacancyPercentage $_{t} \sim N\left(\mu, \sigma^{2}\right)$

Where subscript $t$ means at time point $t$; $\mu$ : mean, also the mathematical expectation; $\mu+1.96 \sigma$ : upper limit of $95 \%$ confidence interval; $\mu-1.96 \sigma$ : lower limit of $95 \%$ confidence interval.

The result of the probability distribution of vacancy was a $3 \times 144$ matrix, as shown in Equation (5).

$$
\begin{aligned}
& \text { Probability distribution of vacancy } \text { sample size } 100 \text { households }= \\
& \mu_{1} \quad \text { timeline } \\
& \mu+1.96 \sigma \quad\left[\begin{array}{ccc}
\mu_{1} & \cdots & \mu_{144} \\
(\mu+1.96 \sigma)_{1} & \ddots & (\mu+1.96 \sigma)_{144}
\end{array}\right] \\
& \mu-1.96 \sigma \quad\left[\begin{array}{lll}
(\mu-1.96 \sigma)_{1} & \cdots & (\mu-1.96 \sigma)_{144}
\end{array}\right]
\end{aligned}
$$

The above data processing was applied to all sample sizes and all three household types. The results provide the matrix of probability distribution of vacancy for every sample size and every type of household. Equation (6) is a 4D matrix showing the results.

$$
\left(\begin{array}{c}
\mu \\
\mu \\
\mu+1.96 \sigma \\
\mu-1.96 \sigma
\end{array} \quad\left[\begin{array}{ccc}
\mu_{1} & \text { Probability distribution of vacancy }= \\
(\mu+1.96 \sigma)_{1} & \ddots & (\mu+1.96 \sigma)_{144} \\
(\mu-1.96 \sigma)_{1} & \cdots & (\mu-1.96 \sigma)_{144}
\end{array}\right] \text {, sample size, household size }\right)
$$

\subsubsection{Vacancy modelling for Danish households}

To assign the above probability distribution of vacancy to Danish households, we used the data from Statistics Denmark (2017). Table 1 shows the numbers of households of different household size and different floor area in apartment buildings in Demark in 2017.

Table 1 Numbers of households of different household size and different apartment size in Danish apartment buildings, data source: Statistics Denmark (2017).

\begin{tabular}{cccc}
\hline Area $\left(\mathbf{m}^{\mathbf{2}}\right)$ & $\mathbf{1}$ person & $\mathbf{2}$ persons & $\mathbf{3}$ persons \\
\hline $\mathbf{5} \mathbf{5 0}$ & 124660 & 23316 & 3249 \\
$\mathbf{5 0 - 7 4}$ & 369649 & 125687 & 27181 \\
$\mathbf{7 5 - 9 9}$ & 266876 & 206708 & 73749 \\
$\mathbf{1 0 0 - 1 2 4}$ & 115590 & 173653 & 69038 \\
$\mathbf{1 2 5 - 1 4 9}$ & 64284 & 152127 & 54997 \\
$\mathbf{1 5 0 - 1 7 4}$ & 34275 & 103633 & 40123 \\
$\mathbf{> 1 7 5}$ & 33985 & 110574 & 46796 \\
\hline
\end{tabular}

As shown in Table 1, for different apartment size, the distributions of household size is different. Set oneperson households account for $a \%$, two-person households account for $b \%$ and three-person households account for $c \%$ (where $a \%+b \%+c \%=1$ ). Then, matrixes of Equation (1)-(3), (5) and (6) for every sample size and every type of household were aggregated according to the three percentages. The 
aggregation process was not direct addition of the matrixes above, because the sum of standard deviations of two normally distributions follows the rule shown in Equation (7).

$\sigma_{\text {new }}=\sqrt{\left(\sigma_{1}\right)^{2}+\left(\sigma_{2}\right)^{2}}$

Therefore, for apartment buildings in Denmark, the Probability distribution of vacancy is given by Equation (8).

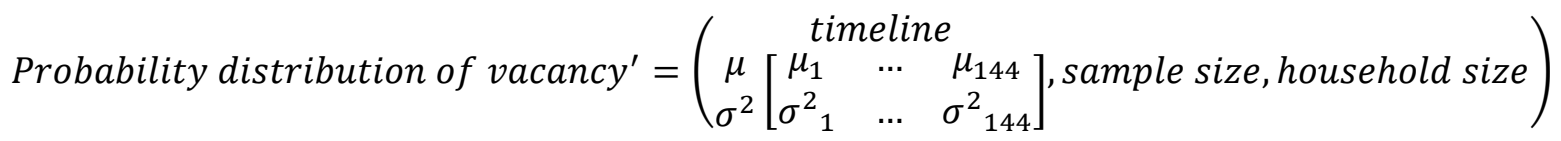

Then, the aggregation of Probability distribution of vacancy' of different sample size is shown in Equation (9).

Probability distribution of vacancy aggregated $^{\prime}=$ $a \% \cdot$ Probability distribution of vacancy one-person household $^{\prime}+$

$b \% \cdot$ Probability distribution of vacancy ${ }_{\text {two-person household }}{ }^{\prime}+$

$c \% \cdot$ Probability distribution of vacancy three-person household $^{\prime}$

$=\left(\begin{array}{c}\mu\left[\begin{array}{ccc}\mu_{1} & \cdots & \mu_{144} \\ \sigma^{2}{ }_{1} & \ldots & \sigma^{2}{ }_{144}\end{array}\right] \text {, sample size }\end{array}\right)$

Finally, the Probability distribution of vacancy aggregated $^{\prime}$ is shown in Equation (10).

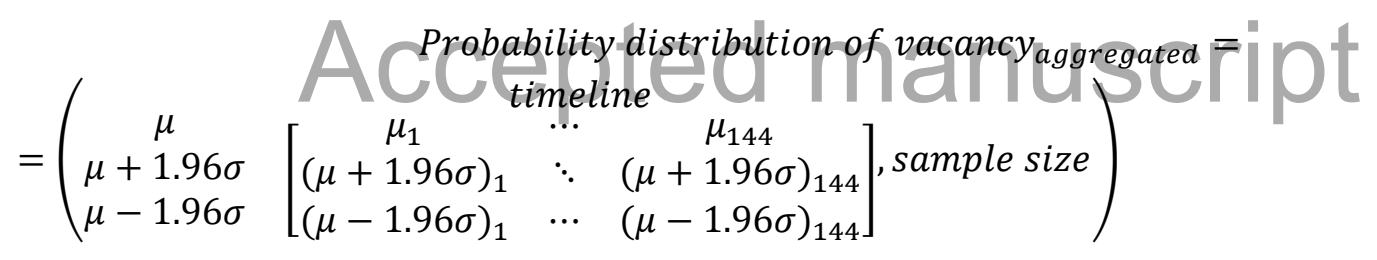

Probability distribution of vacancy aggregated (Equation 10) is a 3D matrix where the first two dimensions are similar to Equation (5) and the third dimension is the sample size.

According to Table 1, a lumped distribution of household size can be obtained as $a \%$ is $45.5 \%, b \%$ is $40.3 \%$ and $c \%$ is $14.2 \%$. Based on the lumped distribution of household size, Fig. 3 shows distributions of vacancy from three different sample sizes in the matrix Probability distribution of vacancyaggregated. 

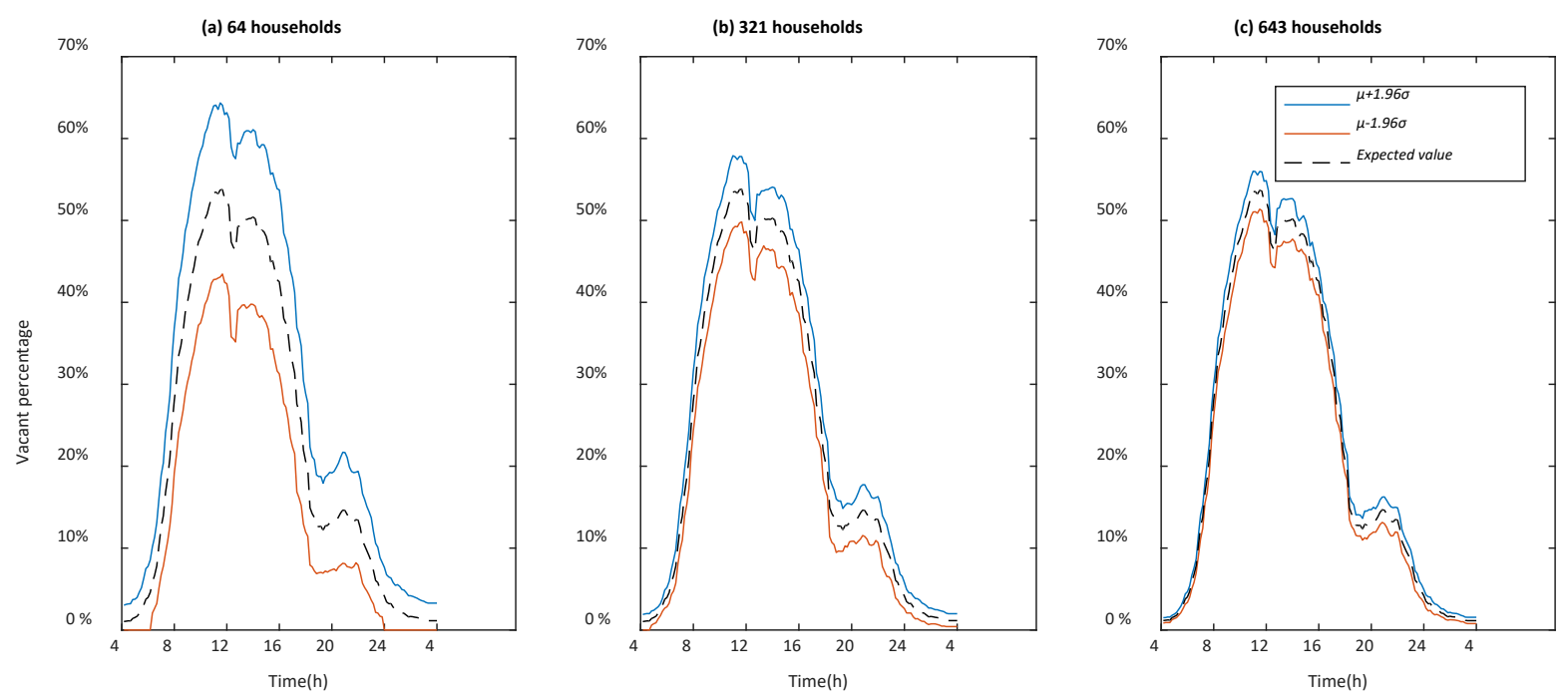

Fig. 3 Vacancy profile of groups with different number of households: (a) 64 households, about 100 people; (b) 321 households, about 500 people; (c) 643 households, about 1000 people.

As shown in Fig. 3, the expected value of the vacant percentage does not change with the number of households. However, $\sigma$ becomes smaller and smaller with more households aggregated. In other words, the uncertainty of the vacant percentage decreases when the number of households becomes larger.

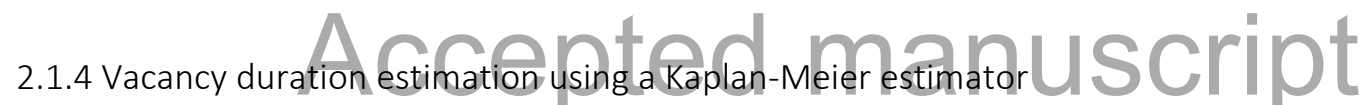

The method of survival analysis (Kaplan-Meier estimator) was applied to estimate vacancy duration, to estimate how long occupants are away from home. The Kaplan-Meier estimator, also known as the product limit estimator based non-parametric statistic, is used to compute probabilities of occurrence of an event from a certain moment (Goel et al. 2010). The estimator is given by:

$S(t)=\prod_{i: t_{i}}\left(\frac{n_{i}-d_{i}}{n_{i}}\right)$

Where $n_{i}$ is the number of actions on-going at time $t_{i}$ and $d_{i}$ is the number of actions ended.

The followings steps were applied to obtain occupancy data for each household size.

1. Without resampling, the initial matrix InitialOccupancyData as below is used for survival analysis.

InitialOccupancyData(household serial number, timeline) timeline

$=\begin{gathered}\text { house }_{1} \\ \text { house }_{n}\end{gathered}\left[\begin{array}{ccc}s_{1}^{1} & \cdots & s_{1}^{144} \\ \vdots & \ddots & \vdots \\ s_{n}^{1} & \cdots & s_{n}^{144}\end{array}\right]\left(s_{i}^{t}=1\right.$ or 0$)$

2. There are 144 time points in the timeline. For each point, find all the vacant households at this moment and then calculate the vacancy duration (from this moment to the future). Then the matrix SurvivalTimeLength is generated. 
SurvivalTimeLength $=\begin{gathered}\text { house }_{1} \\ \vdots \\ \text { house }_{n}\end{gathered}\left[\begin{array}{ccc}d_{1}^{1} & \cdots & d_{1}^{144} \\ \vdots & \ddots & \vdots \\ d_{n}^{1} & \cdots & d_{n}^{144}\end{array}\right]$

Where $d_{i}^{t}$ is the vacancy duration at moment $t$ of house $e_{i}$, especially $d=0$ means occupancy.

3. For every time point (1 144), using the Kaplan-Meier Estimator to estimate the probability of a given vacancy duration.

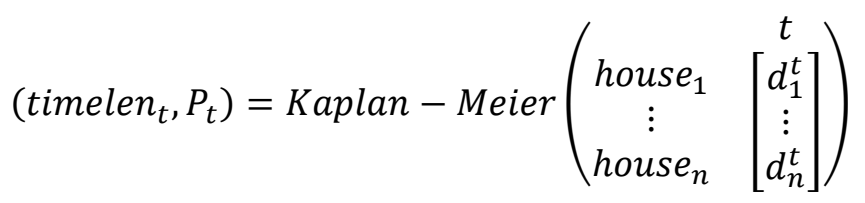

Where $t$ means time point $t, t=1,2, \ldots, 144$. timelen $_{t}, P_{t}$ are output columns. timelen $_{t}$ is a column of survival time lengths from time point $t . P_{t}$ is a column of corresponding probabilities at time point $t$.

The probabilities of vacancy duration for all three household sizes are shown in Fig. 4. It is the aggregation of results from all 144 points. The figure shows the probability that a dwelling is vacant at any observation states and onwards. For example, for one-person households, if a dwelling is unoccupied at 8:00 (see xaxis), the probability that it is still unoccupied after two hours (see $y$-axis) is around $80 \%$ (colour bar) and after six hours it is around $60 \%$.

\section{Accepted manuscript}



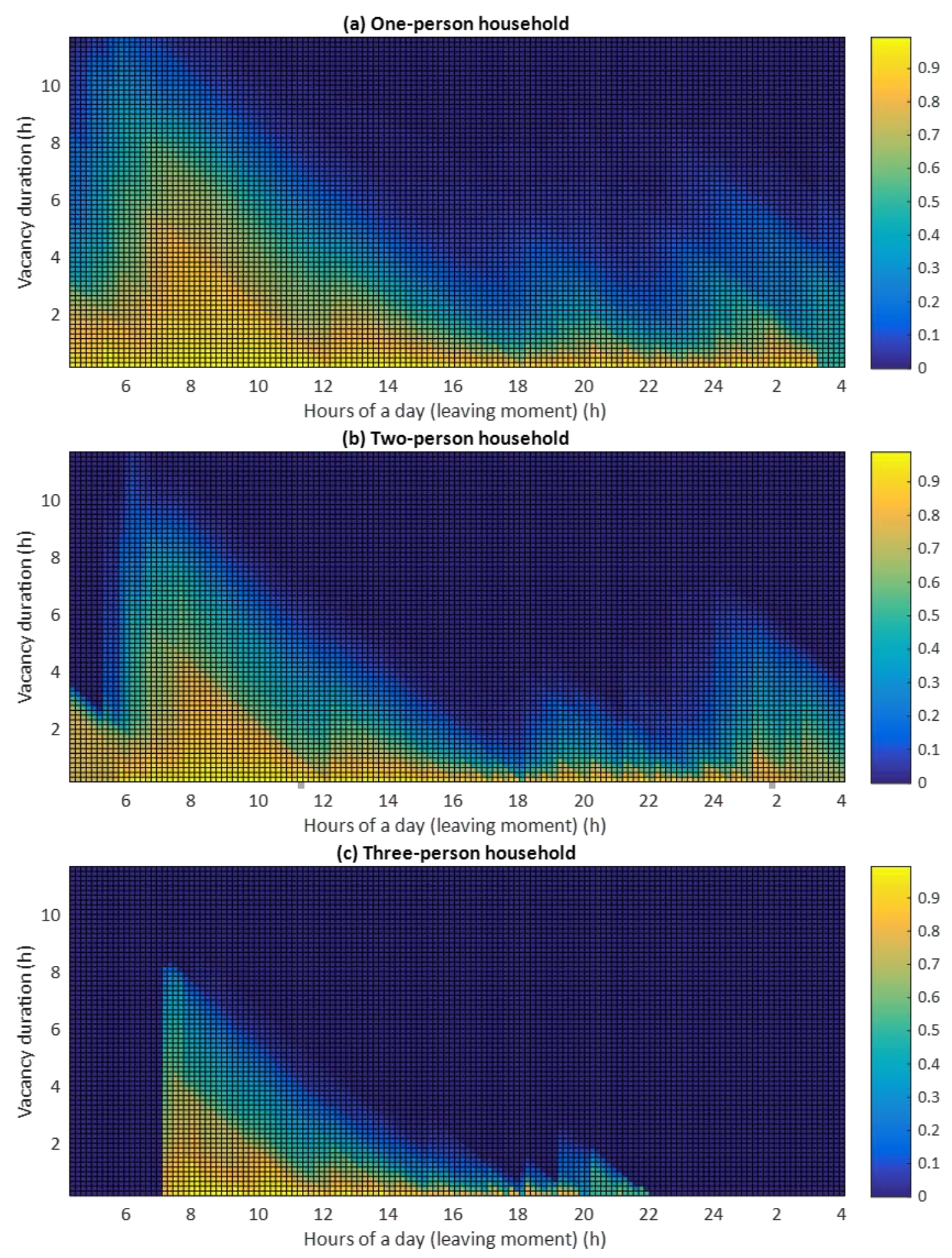

Fig. 4 Survival analysis of vacancy for all 144 time points and three household sizes.

\subsection{Building modelling}

White-box modelling, black-box modelling, and grey-box modelling are the three approaches commonly used in the dynamic simulation of buildings. White-box models consist of heat transfer equations of a 
building using the detailed thermal physical parameters of the building. Such a model is too complex for the simulation of building clusters as it would result in a decrease in computing speed when scaling-up. Black-box models are totally data-driven. The models are thus not applicable for modeling building clusters with a large number of buildings. A Grey-box model is the combination of a white-box model (physical mechanism) and a black-box model (data-driven model), resulting in higher computing speed and wider applicability.

In this study, grey-box models were developed for building simulation. The grey-box model consists of a space heating system, a building RC model (a lumped parameter model) and building thermal parameters.

\subsubsection{Space heating system}

In this study, the households' need for space heating were fulfilled by heat pump-based floor heating. The COP of a heat pump is a complex function with many variables. However, for higher simulation speed, the simplification was made that only the most important variable, outdoor air temperature $T_{\text {outair }}^{t}$, was included in the heat pump COP equation (Bhattarai et al. 2014). This is of appropriate complexity for the present study.

COP $=0.078 T_{\text {outair }}^{t}+2.791$

Floor heating heat transfer includes: 1) convection heat transfer between floor and indoor air, and 2) radiation heat transfer between floor and envelope, floor and inner walls. The floor heating heat transfer equations are as follows (Equations 16-18), when the floor heating is on.

For convection heat transfer

$Q_{\text {floor }}^{\text {conv }}=5 \times 10^{-8} A_{\text {floor }}\left(T_{\text {floor }}-T_{i}^{t}\right)^{1.31}$

Where $Q_{\text {floor }}^{\text {conv }}(\mathrm{W})$ is heat transfer though convection, $A_{\text {floor }}\left(\mathrm{m}^{2}\right)$ is floor area, $T_{\text {floor }}\left({ }^{\circ} \mathrm{C}\right)$ is the temperature of surface of floor and $T_{i}^{t}\left({ }^{\circ} \mathrm{C}\right)$ is indoor air temperature at time $t$.

For radiation heat transfer between floor and envelope

$Q_{\text {floor }}^{\text {rad-om }}=2.13 A_{\text {om-wall }}\left(\left(T_{\text {floor }}+273.15\right)^{4}-\left(T_{o m}^{t}+273.15\right)^{4}\right)$

Where $Q_{\text {floor }}^{\text {rad-om }}(\mathrm{W})$ is heat transfer though radiation between floor and envelope, $A_{\text {om-wall }}(\mathrm{m} 2)$ is envelope area and $T_{o m}^{t}\left({ }^{\circ} \mathrm{C}\right)$ is envelope temperature at time $t$.

For radiation heat transfer between floor and inner walls

$Q_{\text {floor }}^{\text {rad-im }}=2.13 A_{\text {im-wall }}\left(\left(T_{\text {floor }}+273.15\right)^{4}-\left(T_{\text {im }}^{t}+273.15\right)^{4}\right)$

Where $Q_{\text {floor }}^{\text {rad-im }}(\mathrm{W})$ is heat transfer though radiation between floor and inner walls, $A_{\text {im-wall }}\left(\mathrm{m}^{2}\right)$ is inner wall area and $T_{i m}^{t}\left({ }^{\circ} \mathrm{C}\right)$ is inner wall temperature at time $t$. 
Due to building thermal inertia, when floor heating is switched off, the floor is still warm. The floor heating time constant $t_{\text {floor }}$ is assumed to be 30 minutes. The equations thus take the following form when floor heating is switched off at time $t_{0}$.

$Q_{\text {floor }}^{t}=Q_{\text {floor }}^{t_{0}} e^{-\left(\frac{t-t_{0}}{t_{\text {floor }}}\right)}$

Where $Q_{\text {floor }}$ is $Q_{\text {floor }}^{\text {conv }}$ or $Q_{\text {floor }}^{\text {rad-om }}$ or $Q_{\text {floor }}^{\text {rad-im }}$.

In order to achieve an appropriate simulation speed, another simplification was made: the surface temperature of the floor was set to $26^{\circ} \mathrm{C}$ (in human body comfort zone) when floor heating is on.

\subsubsection{RC model}

An RC model is a lumped parameter model, regarding a building as a whole for the purpose of simulation. There are three states used to describe the development of the indoor temperature. The first state $T_{i}\left({ }^{\circ} \mathrm{C}\right)$ is indoor air temperature. The second state $T_{o m}\left({ }^{\circ} \mathrm{C}\right)$ is building envelope temperature as influenced by the building heat transfer with outside air. The last state $T_{i m}\left({ }^{\circ} \mathrm{C}\right)$ is inner walls temperature that reflects the influence of buildings' thermal inertia on indoor temperature (Thavlov 2008), (EZilio 2016) and (Sarran 2016). Fig. 5 shows the structure of the model used in this study. Five heat transfer pathways are included in the RC model.

1. Air-wall and air-window convective heat transfer

2. Solar radiation

3. Human body and household appliance heat emission

4. Mechanical ventilation (with heat recovery in new buildings) and air leakage

5. Thermal bridge heat loss

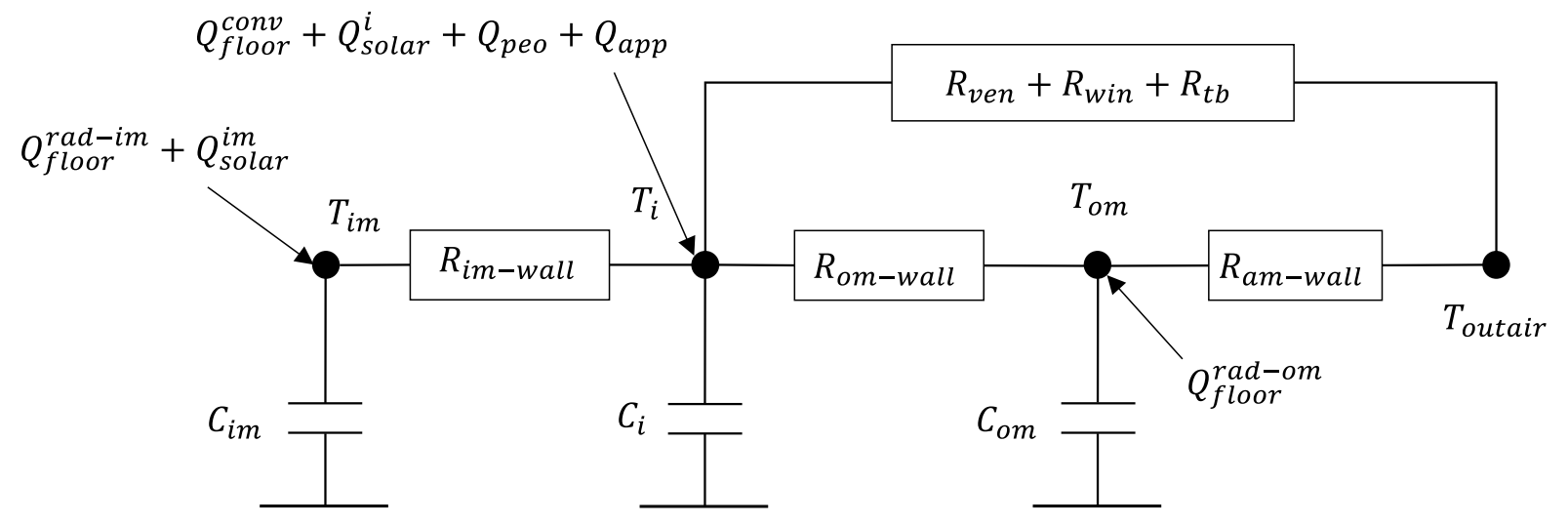

Fig. 5 4R3C grey-box model structure

For indoor air 
$C_{i} \frac{d T_{i}^{t}}{d t}=A_{\text {im-wall }} h_{\text {im }}\left(T_{\text {im }}^{t}-T_{i}^{t}\right)+A_{\text {om-wall }} h_{\text {om }}\left(T_{o m}^{t}-T_{i}^{t}\right)+A_{\text {win }}\left(1-p_{\text {solar-rad }}\right) E_{\text {solar }}+$ $\left(E_{\text {people }}+E_{\text {app }}\right)+C_{i}\left(A C H_{\text {ven }}\left(1-p_{\text {exchanger }}\right)+A C H_{\text {leak }}\right)\left(T_{\text {outair }}^{t}-T_{i}^{t}\right)+\left(A_{\text {win }} h_{\text {win }}+\left(A_{\text {win }}+\right.\right.$

$\left.\left.A_{\text {om-wall }}\right) h_{t b}\right)\left(T_{\text {outair }}^{t}-T_{i}^{t}\right)+Q_{\text {floor }}^{\text {conv }}$

Where $C_{i}(\mathrm{~J} / \mathrm{K})$ is the thermal capacity of indoor air, $h_{i m}\left(\mathrm{~W} /\left(\mathrm{m}^{2} \cdot \mathrm{K}\right)\right)$ is the convection heat transfer coefficient between indoor air and inner wall, $h_{o m}\left(\mathrm{~W} /\left(\mathrm{m}^{2} \cdot \mathrm{K}\right)\right)$ is the convection heat transfer coefficient between indoor air and envelope, $h_{\text {win }}\left(\mathrm{W} /\left(\mathrm{m}^{2} \cdot \mathrm{K}\right)\right)$ is the convection heat transfer coefficient between indoor air and window, $A_{\text {win }}\left(\mathrm{m}^{2}\right)$ is the window area, $p_{\text {solar-rad }}(\%)$ is the percentage of solar radiation absorbed by inner walls, $p_{\text {exchanger }}(\%)$ is the heat recovery efficiency, $E_{\text {solar }}\left(\mathrm{W} / \mathrm{m}^{2}\right)$ is the solar radiation intensity, $E_{\text {people }}, E_{\text {app }}(\mathrm{W})$ are the heat dissipation rate of people and household appliances, $\mathrm{ACH}_{\mathrm{ven}}\left(\mathrm{s}^{-1}\right)$ is the mechanical ventilation air change rate and $A C H_{\text {leak }}\left(\mathrm{s}^{-1}\right)$ is the air change rate due to air leakage through the facade.

For the building envelope

$C_{o m} \frac{d T_{o m}^{t}}{d t}=A_{\text {om-wall }} h_{\text {om }}\left(T_{i}^{t}-T_{\text {om }}^{t}\right)+A_{\text {am-wall }} h_{\text {am }}\left(T_{i}^{t}-T_{\text {outair }}^{t}\right)+Q_{\text {floor }}^{\text {rad }}$

Where $C_{o m}(\mathrm{~J} / \mathrm{K})$ is the thermal capacity of the building envelope, $A_{\text {am-wall }}\left(\mathrm{m}^{2}\right)$ is the surface area of the building envelope and $h_{a m}\left(\mathrm{~W} /\left(\mathrm{m}^{2} \cdot \mathrm{K}\right)\right)$ is the convection heat transfer coefficient between outdoor air and the building envelope.

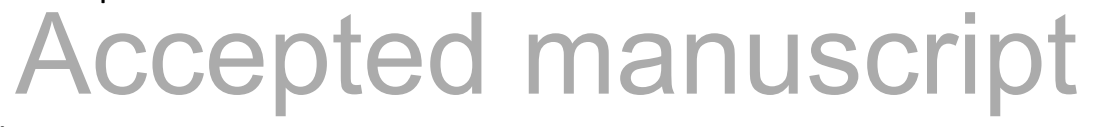

For the inner walls

$C_{i m} \frac{d T_{i m}^{t}}{d t}=A_{\text {im-wall }} h_{\text {im }}\left(T_{i}^{t}-T_{\text {im }}^{t}\right)+A_{\text {win }} p_{\text {solar-rad }} E_{\text {solar }} \frac{A_{\text {im-wall }}}{A_{\text {floor }}+A_{\text {im-wall }}}+Q_{\text {floor }}^{\text {rad-im }}$

Where $C_{i m}(\mathrm{~J} / \mathrm{K})$ is the thermal capacity of the inner walls.

Then, discretization of the equations above for computer simulation.

$C_{x} \frac{d T_{x}^{t}}{d t}=C_{x} \frac{T_{x}^{t}-T_{x}^{t-1}}{\Delta t}$

Where the time interval $\Delta t$ is 60 seconds in this study. This relatively short time interval was used for two reasons. First, to provide electrical demand flexibility to power grids, the response time of services has to be short. Second, the current models are relatively small and the simulation run time is short, so with even 60 seconds time interval, the run time for a 1000 households is only 2 minutes.

\subsubsection{Building thermal parameters}

Using the developed RC model and the space heating model, the building model was established. Based on the TABULA database, representative building types can be extracted for case study-based analysis. We chose only apartment blocks for the case study, as they have a large energy demand. Table 2 shows the $U$ values of the building envelope of apartment blocks used in the case study. 
Table 2 U values of building envelopes, data source: TABULA (TABULA 2015)

\begin{tabular}{cccccc}
\hline \multirow{2}{*}{ Year of construction } & \multirow{2}{*}{ Energy standard } & \multicolumn{4}{c}{ U values $\left(\mathbf{W} /\left(\mathbf{m}^{2} \mathbf{K}\right)\right)$} \\
\cline { 3 - 6 } & & Roof & Wall & Floor & Window \\
\hline \multirow{3}{*}{$1961-1972$} & Existing state & 0.33 & 0.51 & 0.99 & 2.7 \\
& Usual Refurbishment & 0.12 & 0.34 & 0.24 & 1.4 \\
& Advanced Refurbishment & 0.09 & 0.33 & 0.14 & 0.9 \\
\hline \multirow{2}{*}{$1979-1998$} & Existing state & 0.19 & 0.34 & 0.19 & 2.7 \\
& Usual Refurbishment & 0.12 & 0.34 & 0.19 & 1.4 \\
& Advanced Refurbishment & 0.09 & 0.34 & 0.19 & 0.9 \\
\hline \multirow{2}{*}{$\mathbf{2 0 1 1 \sim}$} & National minimum requirement & 0.1 & 0.18 & 0.14 & 1.05 \\
& Improved standard & 0.1 & 0.16 & 0.1 & 0.8 \\
& Ambitious standard/NZEB & 0.08 & 0.16 & 0.08 & 0.8 \\
\hline
\end{tabular}

2.3 Estimating number of households and generating occupancy model for the building

For each apartment block, the number of households of each size, i.e. one-person, two-person and threeperson, were estimated according to Statistics Denmark (2017). The dwelling size of an apartment block in Denmark approximately follows the normal distribution shown in Equation (24).

DwellingSize $_{\text {apartment }} \sim N\left(\mu, \sigma^{2}\right), \mu=79, \sigma=25$

For a one apartment building, a random dwelling size can be generated from the above normal distribution. Then, the number of households can be calculated by the following division formula.

$N_{\text {household }}=\operatorname{round}\left(\frac{\text { Floor Area }}{\text { Dwelling Size }}\right)$

Next, the household size can be estimated according to the distributions of household sizes in different dwelling areas, as shown in Table 1.

Finally, an occupancy model of the building can be generated according to the estimation result of number of households of different sizes using the method in 2.1. In the timeline of one day, there are 144 time points with a 10-minute interval. For each point, the mathematical expectation, $\mu+1.96 \sigma$ and $\mu-1.96 \sigma$ of vacancy percentage was determined. In another words, Equation (10) was determined. In the simulation of this building, the occupancy model was then integrated with the building model.

\subsection{Simulation of energy flexibility}

The estimation of the energy flexibility potential of a building cluster was performed in three steps: (i) upward modulation in which heat pumps are turned on at max. power when buildings are unoccupied, (ii) downward modulation in which heat pumps are turned off when buildings are unoccupied, and (iii) subtract power of heat pumps under downward modulation from the power of heat pumps under upward modulation to obtain energy flexibility potential.

In order to facilitate the simulation, 144 time points were transferred to 24 points on the hour. For these 24 time points, the interval was 1 hour. At the beginning of each hour, three values of vacancy percentage 
(expected value, $\mu+1.96 \sigma$ and $\mu-1.96 \sigma$ ) were recorded. Survival analysis of vacancy duration (presented in 2.1.2) was used to predict the decline of vacancy in this hour. Fig. 6 shows an example of a vacancy percentage curve with 24 observation states for the simulation. For vacant households, heat pumps can be switched on or off for energy flexibility. On the other hand, for occupied households, heat pumps are in the state of normal operation, maintaining an indoor air temperature of $22 \pm 2^{\circ} \mathrm{C}$ according to the thermal comfort Category II for the heating season in Standard EN/DS 15251 (EN/DS 15251, 2007).

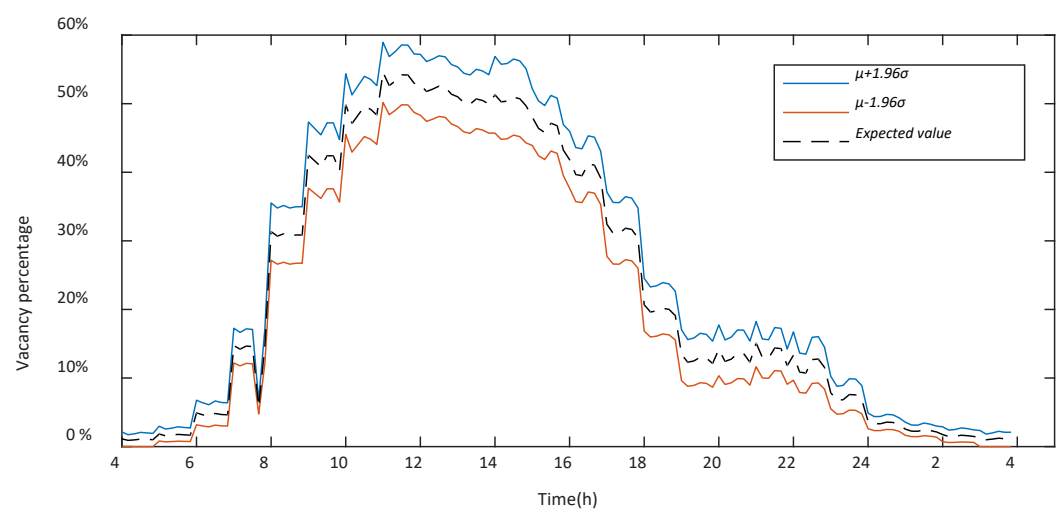

Fig. 6 Shifted vacancy percentage curve, 10 buildings (construction year: 1961 1972), 206 households and 323 people.

The uncertainty of the energy flexibility potential was quantified for building clusters with different scales, to be specific, different numbers of buildings and different numbers of households. This is because the uncertainty of occupancy varies when the number of households changes, as shown in Fig. 3. Quantifying the uncertainty of energy flexibility is important for the energy planning of utility companies. The uncertainty in different scales of building cluster allows utility companies choose an area with a sufficient number of buildings or households to provide the required energy flexibility for certain grid services, such as power balancing at a global level and congestion management that takes account of local factors.

The simulation was run for one day with typical winter weather conditions in Copenhagen. The ambient temperature and solar irradiance are shown in Fig. 7.

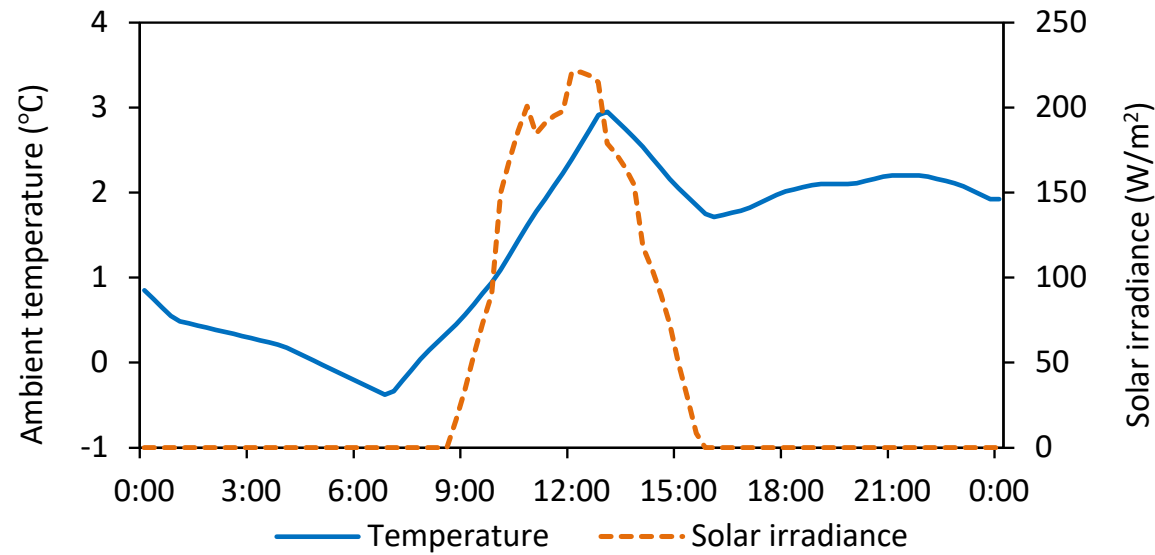

Fig. 7 Dry bulb temperature and solar radiation of one winter day in Copenhagen. 


\section{Results}

\subsection{Energy flexibility potential of building clusters with different construction year}

Fig. 8 is an example showing how indoor air temperature varies under the extreme conditions that all households are vacant for six hours from 9:00 to 15:00. Heat pumps are switched on or off from 9:00 to 14:30 for energy flexibility, but back to normal operation 30 minutes before residents return, to ensure that the room temperature is within the comfort range when residents return. The blue curve is indoor air temperature, while the red curve indicates the control of the heat pumps. As is shown in Fig. 8, (a) is the control mode that heat pumps are switched off during the vacancy period, while (b) is the control mode that heat pumps are switched on during the vacancy period. Both (a) and (b) indicate that if heat pumps return to the state of normal operation (maintaining an indoor air temperature of $22 \pm 2^{\circ} \mathrm{C}$ ) 30 minutes before residents return home, the indoor air temperature can be kept within the comfort zone.

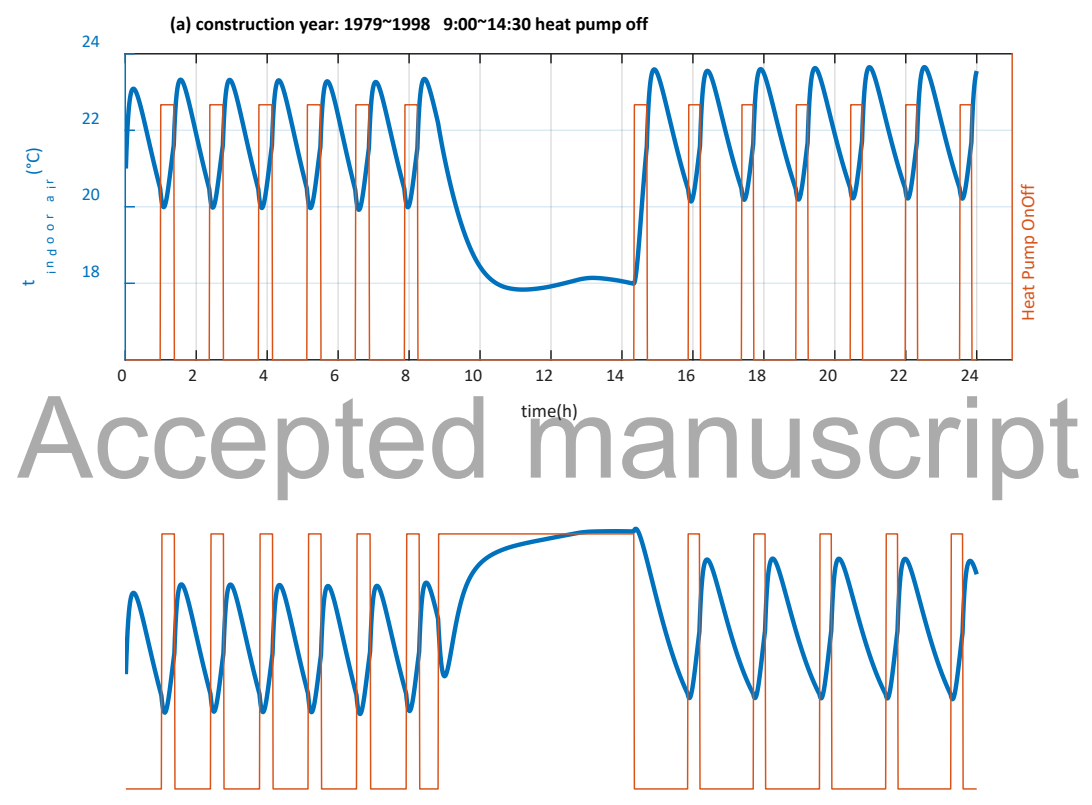

Fig. 8 Indoor air temperature under different control modes.

The heat pump power curve of apartment blocks with three different construction years is shown in Fig. 9, where the gap between the red line and the blue line is building energy flexibility potential. Building clusters with different construction years have different thermal parameters. As it is shown in Table 2, the newer the building is, the better the insulation. In Fig. 9, curves of the three building types indicate that, with a similar number of residents and number of household, the energy consumption by heat pumps in new buildings with better insulation is much less than it is in old buildings. However, old buildings with worse insulation have larger energy flexibility potential (Fig. 10). Fig. 10 shows the subtraction of the red curve and the blue curve in Fig. 9. 

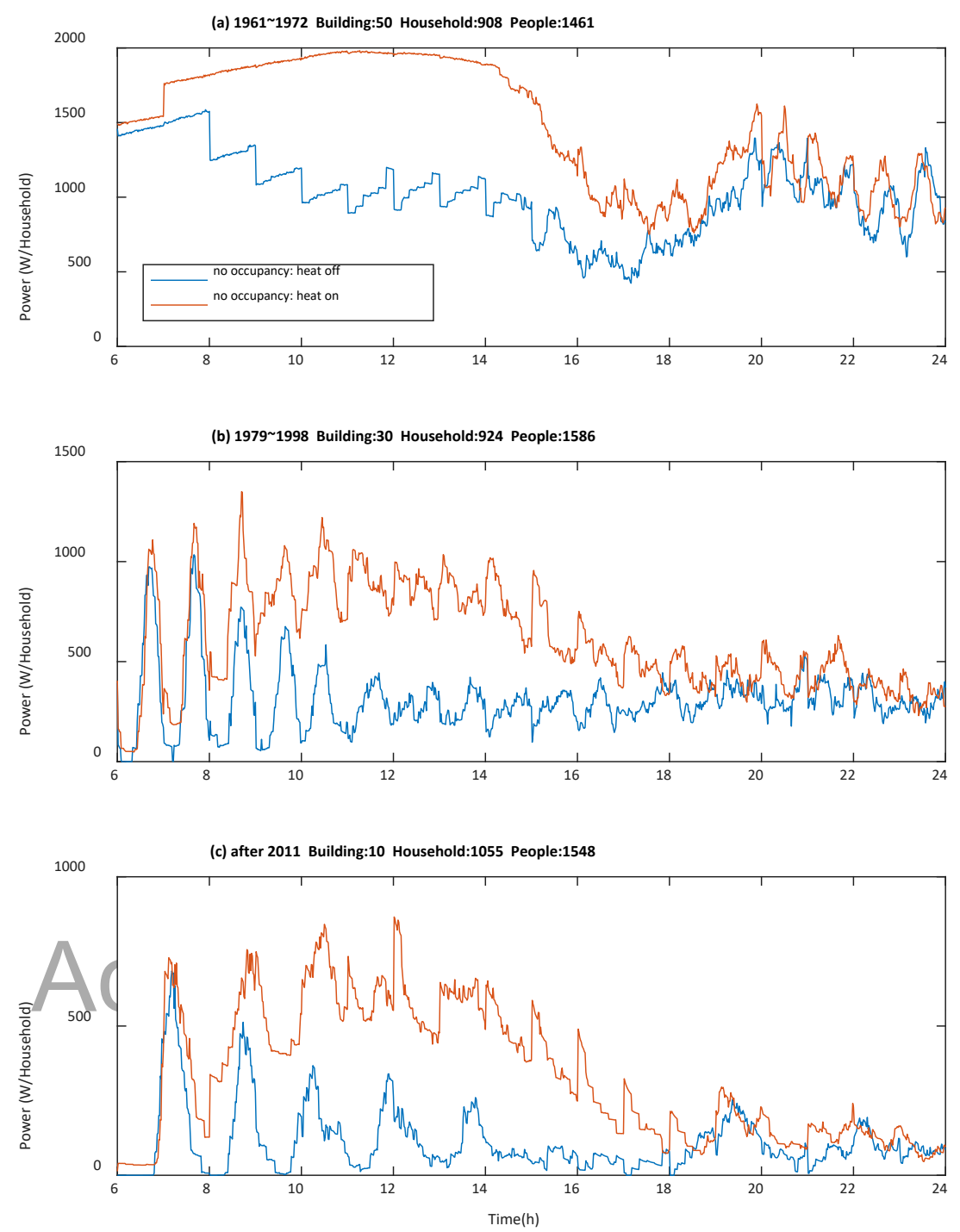

Fig. 9 Heat pump power curve of building cluster with different construction year. The red curve indicates the operation of heat pumps switched on during a vacancy period, while the blue curve indicates heat pumps switched off when the household is vacant. 

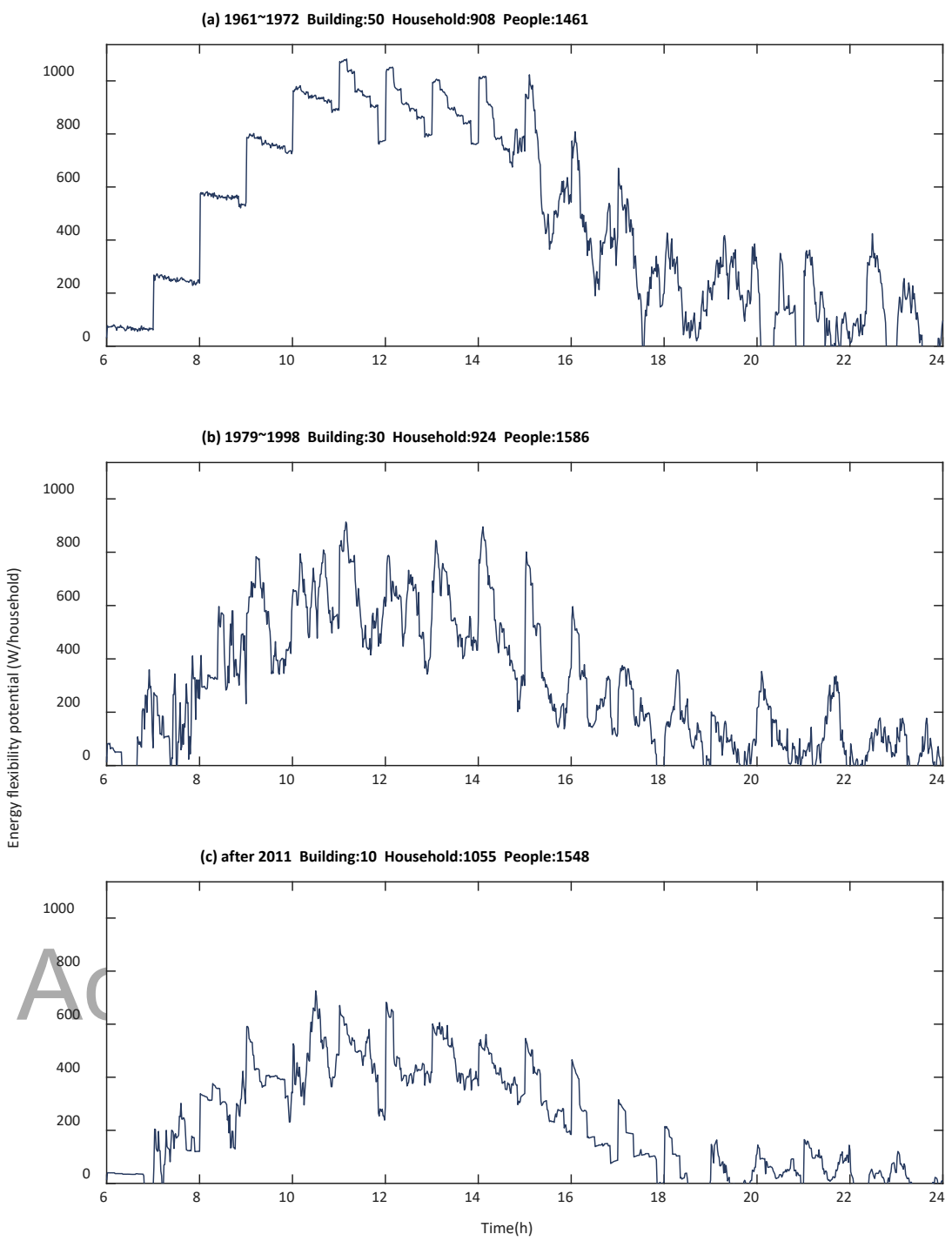

Fig. 10 Building energy flexibility potential (W/household) of building cluster with different construction years

\subsection{Uncertainty of energy flexibility potential of building clusters}

For the occupancy model, with the scaling-up of number of residents and number of households, the mathematical expectation is almost invariable while $\mu+1.96 \sigma$ value and $\mu-1.96 \sigma$ value gradually converge to the mathematical expectation. On condition that heat pumps are switched on or off for energy flexibility according to occupancy patterns, the mean value of energy flexibility potential is determined by the mathematical expectation while the uncertainty of energy flexibility potential is determined by $\mu+1.96 \sigma$ value and $\mu-1.96 \sigma$ value. The uncertainty of the building energy flexibility potential is defined as follows:

Uncertainty $=\frac{E F_{\text {max }}-E F_{\min }}{E F_{\text {mean }}} \%$ 
Where $E F_{\text {mean }}$ is the mean value of energy flexibility potential at any time, which is also the mean value of the adjustable range in Fig. $11 . E F_{\max }$ and $E F_{\min }$ are the maximum value and minimum value of the energy flexibility potential in Fig. 11.

In Fig. 11, it can be seen that the uncertainty declines with the scaling-up of a building cluster. When the number of households is more than 600 and the number of residents is larger than 1000, the uncertainty almost disappears, and the energy flexibility potential can be accurately estimated. Fig. 12 shows that the uncertainty is less than $10 \%$ when the number of households is around 700 . In addition, a building cluster with 1102 households and 1767 residents has energy flexibility with less than 6\% uncertainty.
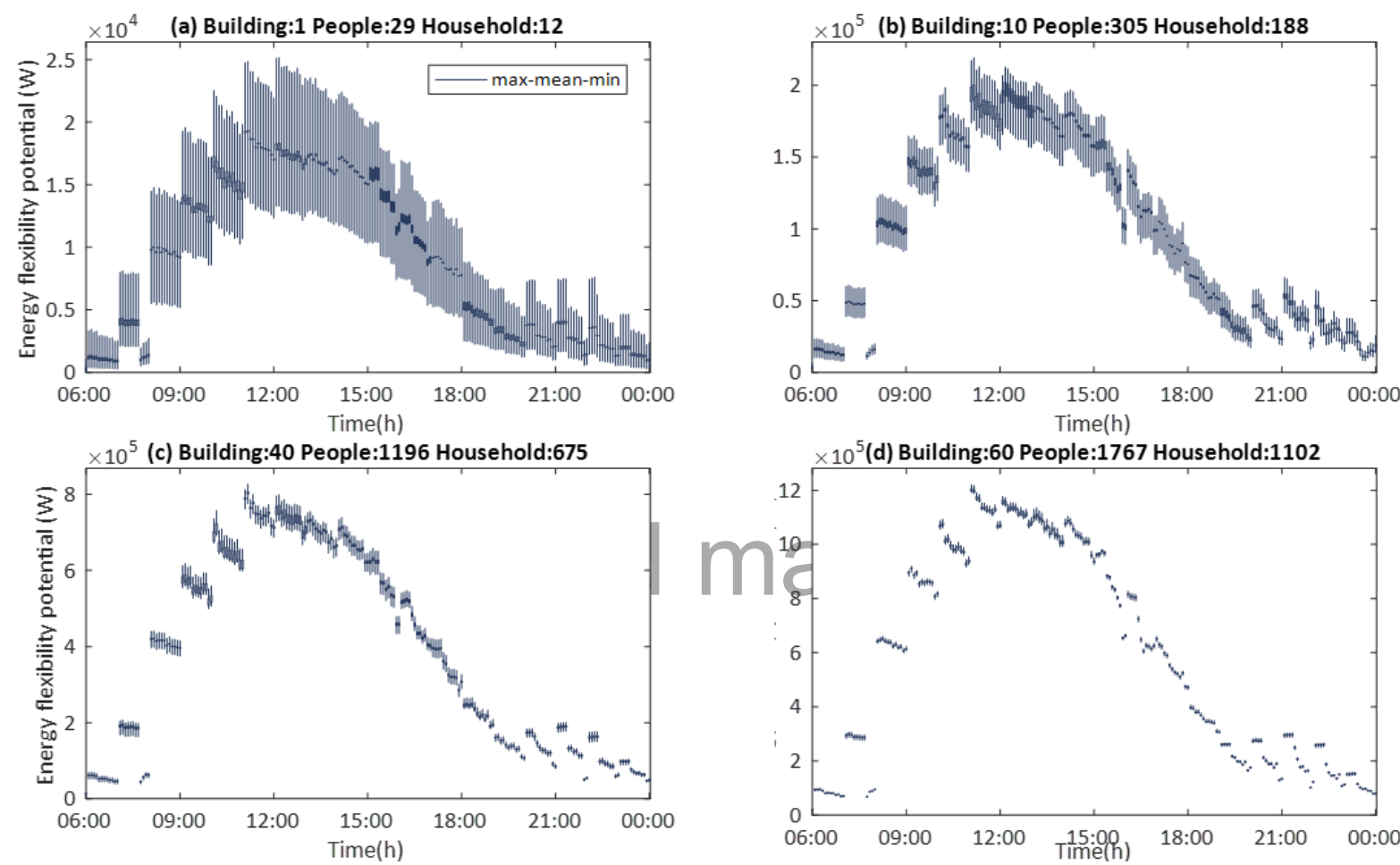

Fig. 11 Energy flexibility and its uncertainty with scaling-up of apartment blocks, existing state, construction year: 1961 1972 


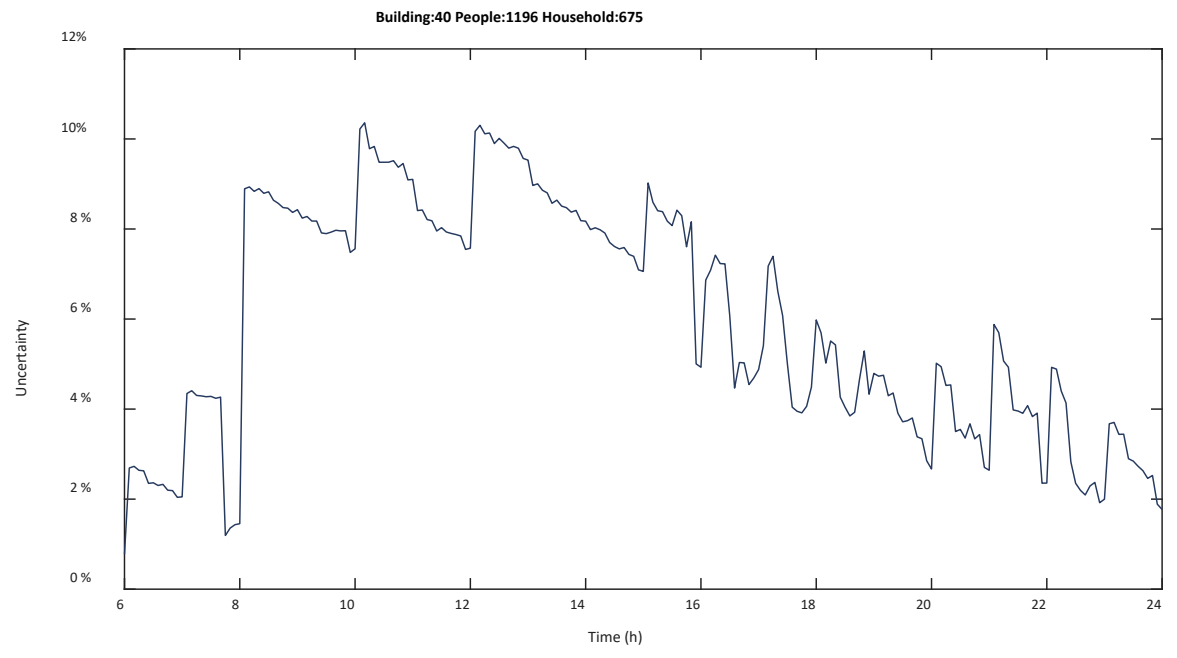

Fig. 12 Uncertainty of building energy flexibility potential, existing state, construction year: 1961 1972

\section{Discussion and Conclusions}

The approach presented in this study is new and takes account of factors that were not covered by previous studies. (Georges et al. 2017) addressed the problem of an aggregator controlling residential heat pumps to offer directly controlled flexibility, with one hundred buildings aggregated in the case study. Compared with the hybrid-model in this study, their modelis static with no means of scaling-up, and does not consider the effect of the uncertainty of occupancy patterns. (Fischer et al. 2017)(Fischer et al. 2016) provided a stochastic bottom-up model for the prediction of space heating and domestic hot water load profile, which contained an occupancy model to evaluate the effect of occupancy pattern uncertainty. However, energy flexibility was not the theme of the article and the model was also a static one where there was no aggregation to form building clusters at different scales. The present approach must be validated against future studies in the field.

Floor heating was considered in this study, but not radiator heating. This may have contributed to the large amount of energy flexibility that was found, as floor heating is more flexible in general (Van Der Heijde et al. 2017). This should be taken into account when the absolute value of the estimation is considered. In the future, forecasting models with different electricity pricing plans must be developed to investigate the energy flexibility of building clusters in the operation phase.

Calibration of RC models is in general a necessary process when using the RC model for predicting or forecasting in building operation. In this study, we determined the $R$ and $C$ values according to the information in the TABULA database in which typical archetypes in Denmark are included. The model accuracy should be validated using measurements from buildings, which we do not yet have. However, this should not be an issue in this study, as the primary objective of this paper is to present the method and procedure developed for the quantification of the uncertainty in energy demand flexibility due to stochastic occupancy. We are currently collecting data in large residential buildings in the Nordhavn area in Copenhagen. The next step is to use these data for RC model validation. We shall then apply this method to the district of Nordhavn to quantify the energy flexibility and its uncertainty for a building cluster. 
In this study, a generic energy flexibility model was developed in MATLAB for the simulation of any dwelling types and for the aggregation of any number of dwellings with high computing speed, usually only a few minutes. Heat pumps were controlled for flexible energy usage when occupants were absent. The heat pump power adjustable range was defined as the energy flexibility during each period. At times when the home was occupied, the indoor temperature was maintained within a comfortable range.

The uncertainty of the building energy flexibility potential caused by the stochasticity of occupancy patterns was evaluated. It was found that when the size of a building cluster was scaled up, the uncertainty became negligible. In other words, the uncertainty of the occupancy decreases when the aggregated number of residents increases. The uncertainty of energy flexibility was less than $10 \%$, when about 700 households were aggregated. In comparison with new buildings with good thermal insulation, older buildings have higher energy flexibility potential. In addition, it was found that the older the building is, the higher the energy flexibility it has.

This model can be a tool for simulating the building energy flexibility potential for district or even regional level energy planning when using the available flexibility to address various challenges caused by fluctuations in the power available from renewable energy sources. Due to the high computing speed of the proposed modelling approach, it can fit the time restrictions of many planning tasks, especially the operational planning that often requires an analysis or a decision to be made only hours ahead of real time operation.

The study is part of two large Danish pilot projects: CITIES - a research project tackling the challenges of smart cities and EnergyLab Nordhavn - a demonstration project that is testing potential solutions. The aim of this study is to develop a data-based modelling framework and associated models for modelling the energy flexibility potential of building clusters. The methods developed are being considered for a number of practical applications, e.g. 1) to support the design of flexibility service products in electricity and heat markets, see reference (You, 2015); 2) to help building demand aggregators to create a buildingbased portfolio that has a statistically steady and predicable performance relation to flexibility control, operation, management and trading; and 3) to facilitate city planning and network planning by providing improved prediction of building clusters' energy profiles, since the original energy profiles are dramatically influenced by using the flexibility of buildings for different purposes.

\section{Acknowledgement}

This study received financial support from two Danish pilot projects, which are EnergyLab Nordhavn: New Urban Energy Infrastructures and CITIES: Centre for IT-Intelligent Energy Systems in cities. The authors would also like to acknowledge IEA EBC Annex67 - Energy Flexible Buildings for providing excellent research networking.

\section{References}

EU, 2009. Directive 2009/28/EC of the European Parliament and of the Council of 23 April 2009 on the Promotion of the Use of Energy from Renewable Sources and Amending and Subsequently Repealing Directives 2001/77/EC and 2003/30/EC. http://eur-europa.eu/eli/dir/2009/28/oj. 
J. Bonke and P. Fallesen. 2010. The impact of incentives and interview methods on response quantity and quality in diary- and booklet-based surveys. Surv. Res. Methods, vol. 4, no. 2, pp. 91-101.

V. Barthelmes, R. Li, R. K. Andersen, W. Bahnfleth, S. P. Corgnati, and C. Rode. 2018 Profiling Occupant Behaviour in Danish Dwellings using Time Use Survey. Submitted to Energy and Buildings, under review.

Wittchen and Kragh 2012. SBi 2012:01 Danish building typologies-Participation in the TABULA project. Danish Building Research Institute, Aalborg University.

TABULA WebTool 2015. http://webtool.building-typology.eu/\#bm.

Li et al. 2017a. Are building users prepared for energy flexible buildings?-A large-scale survey in the Netherlands. Applied Energy 203, 623-634

Fischer, David et al. 2017. "Model-Based Fl Exibility Assessment of a Residential Heat Pump Pool." Energy 118: 853-64. http://dx.doi.org/10.1016/j.energy.2016.10.111.

Fischer, David, Tobias Wolf, Johannes Scherer, and Bernhard Wille-haussmann. 2016. "A Stochastic Bottom-up Model for Space Heating and Domestic Hot Water Load Profiles for German Households." Energy \& Buildings 124: 120-28. http://dx.doi.org/10.1016/j.enbuild.2016.04.069.

Georges, Emeline et al. 2017. "Residential Heat Pump as Flexible Load for Direct Control Service with Parametrized Duration and Rebound Effect." Applied Energy 187: 140-53. http://dx.doi.org/10.1016/j.apenergy.2016.11.012.

Goy, Solène, and Donal Finn. 2015. "Estimating Demand Response Potential in Building cluster." Energy Procedia 78: 3391-96.http://dx.doi.org/10.1016/j.egypro.2015.11.756.

Van Der Heijde, B. et al. 2017. "Unlocking Flexibility by Exploiting the Thermal Capacity of Concrete Core Activation." Energy Procedia 135: 92-104. https://doi.org/10.1016/j.egypro.2017.09.490.

$\mathrm{Li}$, Rongling, Feng Wei, Yang Zhao, and Wim Zeiler. 2017b. "Implementing Occupant Behaviour in the Simulation of Building Energy Performance and Energy Flexibility : Development of Co-Simulation Framework and Case Study." Proceedings of Building Simulation 2017: 1339-46.

Li, Xiwang, Jin Wen, and Ali Malkawi. 2016. "An Operation Optimization and Decision Framework for a Building Cluster with Distributed Energy Systems." Applied Energy 178: 98-109. http://dx.doi.org/10.1016/j.apenergy.2016.06.030.

Lopes, Rui Amaral et al. 2016. "A Literature Review of Methodologies Used to Assess the Energy Flexibility of Buildings." Energy Procedia 91: 1053-58. http://dx.doi.org/10.1016/j.egypro.2016.06.274.

Ma, Li et al. 2016. "Multi-Party Energy Management for Smart Building Cluster with PV Systems Using Automatic Demand Response." Energy and Buildings 121: 11-21.

Pallonetto, Fabiano, Simeon Oxizidis, Federico Milano, and Donal Finn. 2016. "The Effect of Time-of-Use Tariffs on the Demand Response Flexibility of an All-Electric Smart-Grid-Ready Dwelling." Energy and Buildings 128: 56-67. http://dx.doi.org/10.1016/j.enbuild.2016.06.041.

The Danish Government. 2013. "The Danish Climate Policy Plan." The Ministry of Climate, Energy and Building 1(August): 61. http://www.ens.dk/en/policy/danish-climate-energy-policy. 
Vigna, Ilaria, Roberta Pernetti, Wilmer Pasut, and Roberto Lollini. 2018. "New Domain for Promoting Energy Efficiency: Energy Flexible Building Cluster." Sustainable Cities and Society 38(September 2017): 526-33. https://doi.org/10.1016/j.scs.2018.01.038.

You, S. et al. 2015. "The Danish Perspective of Energy Internet: From Service-Oriented Flexibility Trading to Integrated Design, Planning and Operation of Multiple Cross-Sectoral Energy Systems." Zhongguo Dianji Gongcheng Xuebao/Proceedings of the Chinese Society of Electrical Engineering 35(14): 3470-81.

A. Thavlov, Dynamic Optimization of Power Consumption, Master's Thesis, Technical University of Denmark, 2800 Kgs. Lyngby, Denmark, 2008.

E. Zilio, Analysis of building services systems for flexible operation of buildings in smart city district Nordhavn, Master's Thesis, Technical University of Denmark, 2800 Kgs. Lyngby, Denmark, 2016.

L. Sarran, Impact of building design parameters on energy flexibility in Nordhavn district, Master's Thesis, Technical University of Denmark, 2800 Kgs. Lyngby, Denmark, 2016.

Bhattarai, Bishnu Prasad, Birgitte Bak-Jensen, Jaykrishnan Radhakrishna Pillai, and Martin Maier. "Demand flexibility from residential heat pump." In PES General Meeting| Conference \& Exposition, 2014 IEEE, pp. 1-5. IEEE, 2014.

Goel, Manish Kumar, Pardeep Khanna, and Jugal Kishore. Understanding survival analysis: Kaplan-Meier estimate. International journal of Ayurveda research 1, no. 4 (2010): 274.

R.G. Junker, A.G. Azar, R.A. Lopes, K.B. Lindberg, G. Reynders, R. Relan and H. Madsen. Characterizing the energy flexibility of buildings and districts. Applied Energy 225 (2018): 175-182

R. Adhikari, M. Pipatteanasomporn and S. Rahman. An algorithm for optimal management of aggregated HVAC power demand using smart thermostats. Applied Energy 217 (2018): 166-177

C. Finck, R. Li, R. Kramer and W. Zeiler. Quantifying demand flexibility of power-to-heat and thermal energy storage in the control of building heating systems. Applied Energy 209 (2018): 409-425

Shi You, 2015. Report D4.1 Smart network services. http://energylabnordhavn.weebly.com/uploads/3/9/5/5/39555879/d4.1 smart network servic es.pdf

C.Z. Mooney, R.D. Duval, and R. Duvall. Bootstrapping: A nonparametric approach to statistical inference. Sage, 1993.

EN/DS 15251. Indoor environmental input parameters for design and assessment of energy performance of buildings addressing indoor air quality, thermal environment, lighting and acoustics. Dansk Stand., p. 54, 2007. 